\title{
The right bronchial artery Anatomical considerations and surgical approach
}

\author{
HILEL NATHAN, RUBEN ORDA, and MICHEL BARKAY \\ Department of Anatomy and Anthropology, Tel-Aviv University Medical School, \\ Tel-Hashomer Government Hospital, Israel
}

\begin{abstract}
The precise course and relations of the right bronchial artery are presented with an emphasis on the characteristic parallelism between the arches of this artery and the azygos vein. The technique for an easy surgical approach to the bronchial artery is described. Various pathological conditions involving this artery are discussed in relation to possible surgical applications.
\end{abstract}

In spite of the fact that bronchial arteries have been known for a long time, their real function in pulmonary physiology is still under discussion. The participation of these arteries in many pathological conditions of the lungs was the subject of numerous clinical (Cockett and Vass, 1950 ; Cudkowicz and Armstrong, 1951 ; Cudkowicz, 1952 ; Liebow, Hales, and Lindskog, 1949 ; Liebow, Hales, Harrison, Bloomer, and Lindskog, 1950) ; and experimental (Mathes, Holman, and Reichert, 1932 ; Cockett and Vass, 1951) studies. Specially noted were dilatations, particularly where the pulmonary arteries or branches were occluded. In addition, the presence or development of bronchopulmonary precapillary anastomoses was the subject of many investigations (Verloop, 1948 ; Rakshit, 1949 ; Cockett and Vass, 1950, 1951 ; Tobin and Zariquiey, 1953). The importance of these anastomoses in cardiovascular pathology is unquestioned.

Gross anatomical descriptions of bronchial arteries in man and animals are found in the literature (Ruysch, 1721 ; Haller, 1747 ; Cauldwell, Siekert, Lininger, and Anson, 1948 ; Cudkowicz and Armstrong, 1951). These arteries are generally divided, according to their origin and course, into two groups: (a) anterior arteries originating at the internal mammary artery or its branches, and $(b)$ posterior arteries coming from the aorta or its branches (primarily the intercostals). This second group is by far the most important

${ }^{1}$ Former name of Hilel Nathan, one of the authors of the present paper

3The Hebrew University Hadassah Medical School, Jerusalem : The Albert Einstein College of Medicine, Yeshiva University, N.Y. ; Rutgers University, New Brunswick, N.J. ; and our own Department of Anatomy and Anthropology, Tel-Aviv University Medical School systemic blood supply of the lungs. The anterior arteries, on the other hand, are generally small and inconsistent. A complete description of these $\overrightarrow{0}$ vessels and their variations in humans was given. by Cauldwell et al. (1948) and in dogs by Notkovich $^{1}$ (1957).

During the course of hundreds of dissections we noticed that the right bronchial artery was nearly always present and that its course and re- $\mathbb{D}$ lations were consistent. In the present report a $\underset{\overrightarrow{0}}{\overrightarrow{2}}$ detailed description of this vessel and its rela- 을 tions is given in order to facilitate its localization. This might be of practical importance not only항 for anatomists but also for thoracic surgeons and radiologists.

\section{MATERIAL}

Sixty dissecting room cadavers from various medical schools $^{2}$ were studied for this report. The arteries of some specimens were injected with minium or 윽 coloured plastic material.

\section{OBSERVATIONS AND DESCRIPTIONS}

The course of the bronchial artery always originated at the superior border of the first or second right aortic intercostal artery at a variable dis- 0 tance $\left(0.5\right.$ to $5.0 \mathrm{~cm}$.) from the aorta. The bron- $\frac{\Phi}{\Phi}$ chial artery then continued upwards and forwards $\stackrel{\oplus}{?}$ towards the right main bronchus (Figs 1, 2, and 0 3). During its course the artery lay first on the

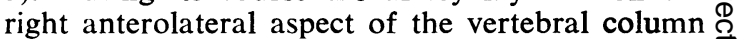
(T3-4), then passed anteriorly on the right of the $\mathbb{\mathbb { Q }}$ thoracic duct and crossed the right side of the $\sigma$ oesophagus to terminate at the lower end of the 


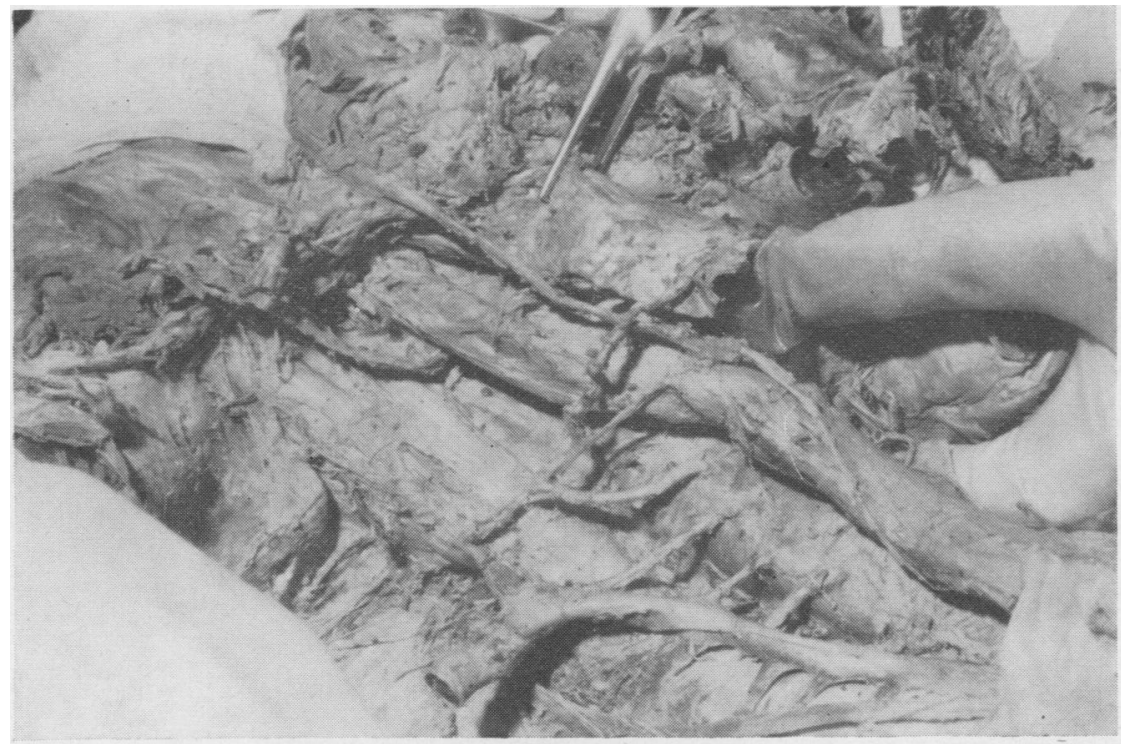

(a)

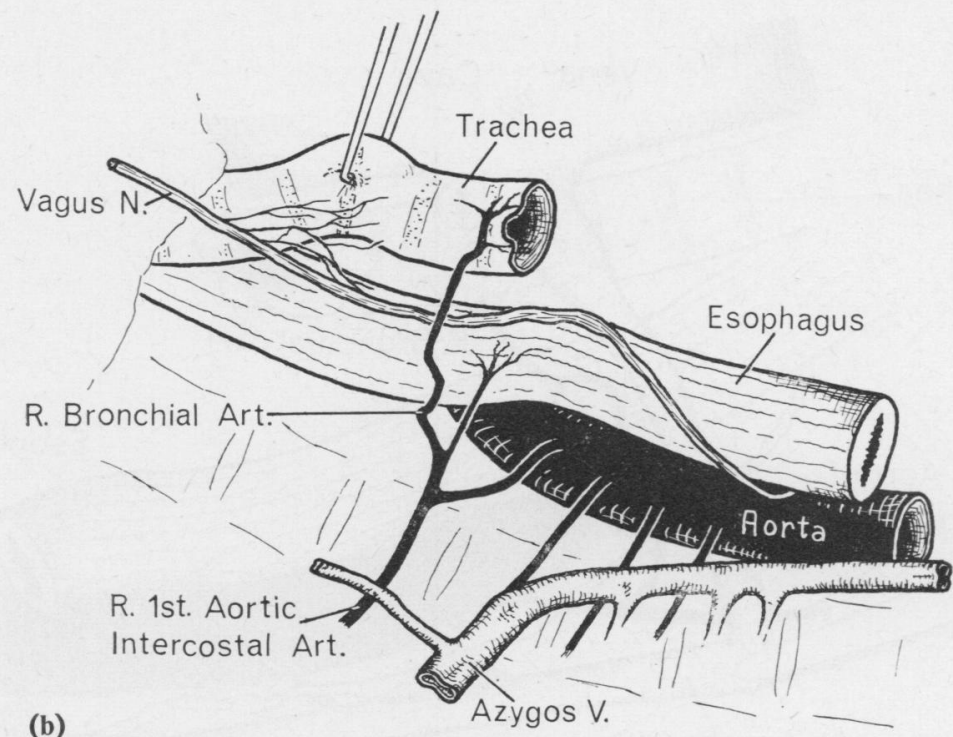

FIG. 1. ( $a$ and $b$ ) Right anterolateral view of the right bronchial artery (R. Bronchial Art.). The different mediastinal organs have been pulled anteriorly in order better to distinguish their borders. The arch of the azygos vein was cut and reclined to the right, allowing a full view of the course of the right aortic intercostal arteries and the right bronchial artery. In this particular case, the course of the right bronchial artery is tortuous. It originates from the superior border of the first right aortic intercostal artery, crosses the oesophagus and the right vagus and finally reaches the trachea and the right bronchus. Note that the first right aortic intercostal artery originates from the anterior aspect of the aorta and that the following intercostal arteries start more laterally. An oesophageal collateral branch is seen. 


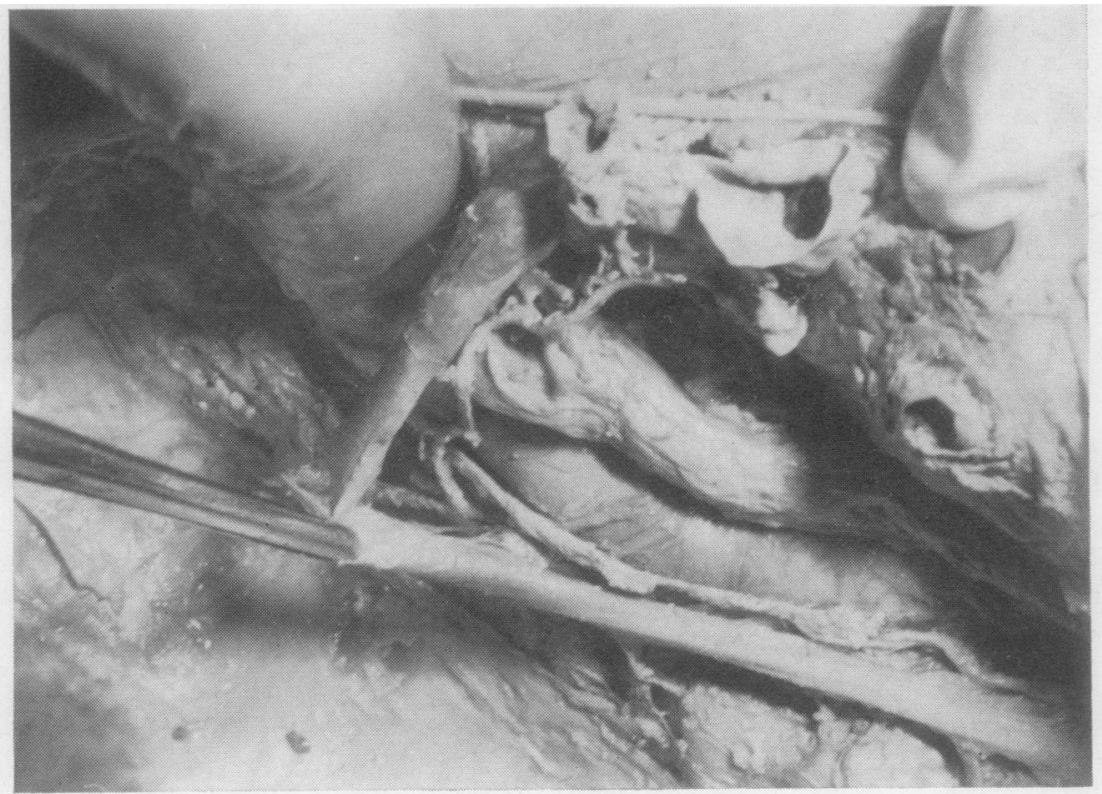

(b)

FIG. 2. ( $a$ and $b$ ) Right anterolateral view of the right bronchial artery (R. Bronchial Art.). In order to emphasize their borders, the mediastinal organs have been pulled forward. The arch of the azygos vein is pulled upwards by forceps, revealing the arch of the right bronchial artery. Note the parallelism between both structures. The thoracic duct ascends between the aorta and the azygos vein in front of the right intercostal arteries. The right bronchial artery crosses the duct on its right side. Note that the first right aortic intercostal arteries originate from the right anterolateral aspect of the aorta. 


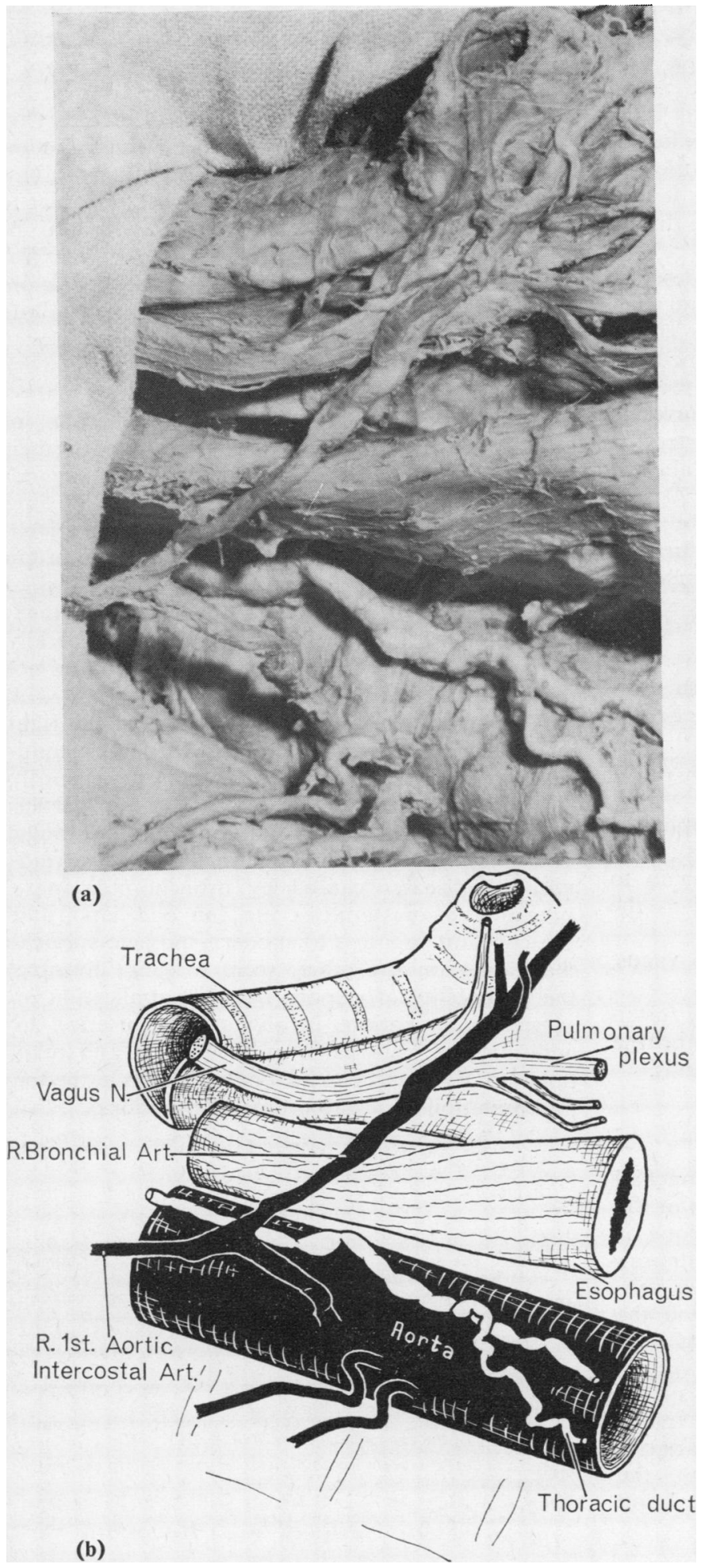

FIG. 3. ( $a$ and $b$ ) Right anterolateral close view of the right bronchial artery $(R$. Bronchial Art.). The right bronchial artery originates from the first right aortic intercostal and crosses the thoracic duct and the oesophagus to reach the trachea and the right bronchus. The organs were drawn anteriorly in order that their borders could be seen more clearly. The trachea was rotated to the left so that its posterior surface is seen. Note that the right bronchial artery crosses the lateral surface of the right vagus, which in this area is divided into a number of branches to form the pulmonary plexus. In this picture the right vagus was slightly displaced downwards from its natural position in the lateral aspect of the trachea. 
trachea and the main bronchus. Here the artery divided into various fine tortuous branches which entered the lung with the bronchus and accompanied the lobar and secondary divisions of the bronchus as classically described. At the level of the trachea, the artery met and crossed the right vagus on the lateral side of the nerve, or it intermingled with branches resulting from the division of the vagus which occurs at that level.

In its mediastinal course the artery described an arch open to the front, downwards and medially. This arch was nearly parallel to the arch of the azygos vein, which was situated immediately anterolateral to the artery on its path to the right bronchus. During this part of their course, the vein totally or partially overlapped the artery.

Although a single artery (frequently following a very tortuous course) was found in $54(90 \%)$ of the dissected specimens, 2 or more right bronchial arteries were occasionally present. In these cases the superior artery adopted the course and relations with the neighbouring structures as previously described for the single right bronchial artery.

Throughout their mediastinal course, the bronchial arteries gave the following branches to organs and tissues in the vicinity:

(a) parietal branches: supplying muscles, vertebrae, ligaments, and pleura ;

(b) visceral branches: supplying the oesophagus, trachea and pericardium, besides the lungs;

(c) vascular branches: as fine vasa vasorum to the aorta and pulmonary vessels as well as the azygos and caval veins ;

(d) branches to the nerves, especially the vagus, the sympathetic and their divisions;

(e) branches to the lymph glands: very often bronchial arteries running to the bronchus on the opposite side were seen perforating the glands.

\section{DISCUSSION}

An easy method for locating the right bronchial artery can be seen as a practical application of the above anatomical description. The technique is as follows: after opening the right hemithorax and the parietal pleura, the lung is drawn ventrally until the arch of the azygos vein and the intercostal vessels are clearly seen through the transparent parietal pleura. The first or second aortic intercostal arteries (which generally supply the 3rd or 4th intercostal space) are then traced to their origin at the aorta. The bronchial arteries will generally be seen branching from the superior border of the 1st or 2 nd intercostal and following the path described above.
Since the arch of the azygos vein is generally $\underset{\vec{S}}{\vec{S}}$ overlapping the bronchial arteries, its presence is 0 an excellent guide for locating these arteries. But the vein should be retracted and displaced. Cut- $\frac{\bar{\sigma}}{}$ ting one or more of the intercostal veins anchor- $\mathbb{\Phi}$ ing the azygos may be necessary in order to allow full exposure of the intercostal arteries in order to reach the bronchial arteries. It should also be $\odot$ noted here that the points of origin of the first right aortic intercostal arteries are usually found on the right anterolateral aspect of the aorta and $\overrightarrow{\overrightarrow{2}}$ not as classically described on the posterior aspect. This point was stressed in a previous work (Nathan, Barkay, and Orda, 1969).

The oblique course, upward and laterally, of $\underset{\infty}{N}$ the first aortic intercostal arteries (due to their $ᄋ$ lower origin on the aorta than their corresponding intercostal spaces) should also be taken into $\bar{z}$ consideration during the procedure. The proximal part of the intercostal artery, from its origin at the aorta to the level where the bronchial artery begins (called by Cauldwell et al. (1948) 'The intercosto-bronchial artery'), is generally larger than the other intercostals which do not have a bronchial artery branch.

The knowledge of the exact course of the right bronchial may not only be of academic anatomical interest. Although it is at present generally neglected in thoracic surgery, it directly participates in pathological conditions of the lungs. Dilatation of the bronchial arteries or cardiovascular diseases caused by broncho-pulmonary precapillary anastomoses, etc., on one hand, and the constant progress of modern thoracic surgical techniques on the other, seem to point towards the probability of a more frequent application of surgical interventions involving these arteries. In addition, the knowledge of the course and relations to this artery may contribute to a better interpretation of arteriograms of the thorax.

\section{REFERENCES}

Cauldwell, E. W., Siekert, R. G., Lininger, R. E., and Anson, B. J. (1948). The bronchial arteries - an anatomic study of 150 human cadavers. Surg. Gynec. Obstet., 86, 395.

Cockett, F. B., and Vass, C. C. N. (1950). The collateral circulation to the lungs. Brit. J. Surg., 38, 97.

(1951). A comparison of the role of the bronchial arteries in bronchiectasis and in experimental ligation of the pulmonary artery. Thorax, 6, 268.

Cudkowicz. L. (1952). The blood supply of the lung in pulmonary tuberculosis. Ibid., 7, 270.

and Armstrong, J. B. (1951). Observations on the normal anatomy of the bronchial arteries. Ibid., $6,343$.

Haller, A. (1747). Icorum anatomicarum quibus praecipuae partes corporis humani, vol. 3, p. 35. Göttingen.

Liebow, A. A., Hales, M. R., and Lindskog, G. E. (1949). Enlargement of the bronchial arteries, and their anastomoses with the pulmonary arteries in bronchiectasis. Amer J. Path., 25, 211. 
- Harrison, W., Bloomer, W., and Lindskog, G. E. (1950). The genesis and functional implications of collateral circulation of the lungs. Yale J. Biol. Med., 22, 637.

Mathes, M. E., Holman, E., and Reichert, F. L. (1932). A study of the bronchial, pulmonary, and lymphatic circulations of the lung under various pathologic conditions experimentally produced. J. thorac. Surg., 1, 339.

Nathan, H., Barkay, M., and Orda, R. (1969). Anatomical observations on the origin and course of the aortic intercostal arteries. $\boldsymbol{J}$. thorac. cardiovasc. Surg., in Press.

Notkovich, H. (1957). The anatomy of the bronchial arteries of the dog. J. thorac. Surg., 33, 242.
Rakshit, P. (1949). Communicating blood vessels between bronchia and pulmonary circulations in the guinea-pig and rat. Quart. J. exp. Physiol., 35, 47.

Ruysch, F. (1721). Opera omnia anatomico-medico-chirurgica Vol. 1: Dilucidatio valvularum, Chap. 4, Obs. 15, pp. 19-22 Fig. 9; Vol. 3: Epistola anatomica problematica sexta (from J. H. Graetz), and Responsio, 1731, pp. 1-11, Tab. 7, Fig. 1-5. Amstelodami, Janssonio-Vaesbergios.

Tobin, C. E., and Zariquiey, M. O. (1953). Some observations on the blood supply of the human lung. Med. Radiogr. Photogr., 29, 9 .

Verloop, M. C. (1948). The arteriae bronchiales and their anastomoses with the arteria pulmonalis in the human lung: a microanatomical study. Acta anat. (Basel), 5, 171. 